\title{
QUALIDADE FISIOLÓGICA DE SEMENTES DE Caesalpinia pyramidalis Tul. DURANTE O ARMAZENAMENTO ${ }^{1}$
}

\author{
LUCICLÉIA MENDES DE OLIVEIRA², RISELANE DE LUCENA ALCÂNTARA BRUNO³, \\ KATIANE DA ROSA GOMES DA SILVA ${ }^{4}$, EDNA URSULINO ALVES ${ }^{3}$, GIVANILDO ZILDO DA SILVA \\ ALBERICIO PEREIRA DE ANDRADE ${ }^{3}$.
}

RESUMO - A catingueira (Caesalpinia pyramidalis Tul.) é uma espécie arbustiva de ampla dispersão no semiárido nordestino e endêmica do bioma caatinga. Airregularidade e má distribuição das chuvas na região comprometem a produção de sementes, a tal ponto que a maioria dos frutos apresenta sementes mal formadas ou inviáveis para a germinação. Dessa forma, o presente trabalho objetivou estudar o comportamento das sementes de Caesalpinia pyramidalis Tul., acondicionadas em diferentes embalagens e ambientes de armazenamento. Os frutos foram coletados em São João do Cariri-PB e levados para o Laboratório de Análise de Sementes da Universidade Federal da Paraíba onde foram beneficiados e, as sementes armazenadas em embalagens de plástico e de vidro, sendo mantidas nas seguintes condições: não controladas de laboratório $\left(27 \pm 3{ }^{\circ} \mathrm{C}\right.$ e $64 \pm 20 \%$ UR); freezer $\left(-18{ }^{\circ} \mathrm{C}\right)$ e câmara seca $\left(19 \pm 5{ }^{\circ} \mathrm{C}\right.$ e $74 \pm 20 \%$ UR) durante 225 dias. Inicialmente e a cada 45 dias as sementes foram submetidas à determinação do teor de água e às seguintes avaliações: primeira e segunda contagem de germinação, índice de velocidade de germinação, comprimento e massa seca das plântulas. Observou-se que a viabilidade e o teor de água das semente são mantidos em todos os ambientes e embalagens estudadas neste trabalho; o vigor das sementes quando analisado pelo teste de primeira contagem é melhor conservado quando as mesmas são acondicionadas em plástico nos ambientes de câmara seca e freezer até o período de 135 dias.

Termos para indexação: germinação, vigor, embalagens, ambientes, catingueira.

\section{PHYSIOLOGICAL QUALITY OF Caesalpinia pyramidalis Tul. SEEDS DURING STORAGE}

\begin{abstract}
The catingueira (Caesalpinia pyramidalis Tul.) is a shrubby species of widespread occurrence in semiarid northeastern and endemic savanna biome. The irregularity and poor distribution of rainfall in the region to undertake seed production, to the point that most fruit has seeds badly formed or non-viable for germination. Thus, this study investigated the behavior of Caesalpinia pyramidalis Tul. seeds put into different packaging and storage ambient. The fruits were collected in São João do Carriri city - PB and taken to the Seed Analysis Laboratory, Universidade Federal da Paraíba where they were processed and the seeds stored in plastic bottles and glass, and kept under the following conditions: non controlled laboratory $\left(27 \pm 3^{\circ} \mathrm{C}\right.$ and $\left.64 \pm 20 \% \mathrm{RH}\right)$, freezer $\left(-18^{\circ} \mathrm{C}\right)$ and dry chamber $\left(19 \pm 5^{\circ} \mathrm{C}\right.$ and $\left.74 \pm 20 \% \mathrm{RH}\right)$ for 225 days. Initially and each 45 days the
\end{abstract}

\begin{abstract}
${ }^{1}$ Submetido em 22/07/2010. Aceito para publicação em 24/10/2010. Parte da Dissertação de Mestrado do primeiro autor apresentada a UFPB. Areia (PB)

${ }^{2}$ Bióloga, doutoranda em Ciência e Tecnologia de Sementes, Cx. Postal 354, CEP: 96001-970, Pelotas-RS, E-mail: lucicleia@biologa.bio.br

${ }^{3}$ Eng. Agr., Profs. Drs. Programa de Pós Graduação em Agronomia PPGA/
\end{abstract}

DFCA/CCA/UFPB, Areia, PB. CEP: 58397-000, riselane@pq.cnpq. br, ednaursulino@yahoo.com.br, albericio@uol.com.br pesquisadores CNPq;

\footnotetext{
${ }^{4}$ Bióloga, bolsista PNPD/CAPES, UFPB, Areia-PB, katrgs@gmail.com

${ }^{5}$ Graduando em Agronomia, Bolsista PIBIC, UFPB. E-mail: givanildozildo@hotmail.com
} 
seeds were submitted to determination of moisture content and the following evaluates: germination first and second count, germination speed index, length and seedling dry mass. It was observed that the viability and seed moisture content is maintained in all ambient and packaging studied in this paper, seed germination when analyzed by the first count test is best preserved when its are wrapped in plastic in a dry chamber and freezer ambient until the period of 135 days.

Index terms: germination, vigor, packaging, ambient, catingueira

\section{INTRODUÇÃO}

A catingueira (Caesalpinia pyramidalis Tul.) pertence à família Caesalpinaceae, espécie arbustiva de ampla dispersão no semiárido nordestino e endêmica do bioma caatinga. Na estação seca perde as folhas para evitar a perda de água por evapotranspiração e logo após iniciarem as primeiras chuvas rebrotam e frutificam. A espécie é tolerante as condições extremas e adapta-se muito bem aos diferentes tipos de solos, incluindo os mais pobres, especialmente os solos pedregosos (Maia, 2004).

A irregularidade e má distribuição das chuvas na região semiárida de um ano para outro (Matallo Júnior, 2000), pode comprometer a produção de sementes de catingueira assim como outras espécies vegetais, a tal ponto que a maioria dos frutos apresenta sementes mal formadas ou inviáveis para a germinação. O caminho para entender as causas das falhas na produção de sementes das espécies florestais nativas, segundo Schorn (2003) consiste em realizar estudos sobre biologia floral, fenologia e comportamento dos seus polinizadores.

As sementes apresentam o maior conteúdo de matéria seca, capacidade germinativa e vigor no estádio de maturidade fisiológica, o qual, geralmente, corresponde ao início da deterioração natural prosseguindo enquanto permanecerem no campo, durante a colheita, processamento e armazenamento. Segundo Krzyzanowski et al. (1999), esta deterioração inicia-se com alterações no sistema de membranas, redução da atividade respiratória e biossintética, germinação lenta, redução do potencial de conservação, menor taxa de crescimento e desenvolvimento, bem como a perda do poder germinativo e morte.

O armazenamento é de fundamental importância na preservação das qualidades físicas, fisiológicas e sanitárias preservando a semente, bem como fornecendo sementes destinadas a pesquisas científicas e à agricultura (Medeiros e Eira, 2006). Armazenamento realizado sob condições adequadas pode minimizar a velocidade de deterioração, permitindo a conservação da viabilidade e do vigor das sementes por um período mais longo do que o obtido em condições naturais (Figliolia e Piña-Rodrigues, 1995).

$\mathrm{O}$ alto teor de água nas sementes combinado com a alta umidade relativa do ar e temperatura do ambiente de armazenamento aceleram a degeneração dos sistemas biológicos, acarretam a perda do vigor e a capacidade de germinação (Azevedo et al., 2003). Por outro lado, sementes com baixos teores de água e baixa temperatura do ambiente de armazenamento propiciam melhores condições para a manutenção da viabilidade, avaliada por meio dos testes de germinação e de tetrazólio (Pontes et al., 2006). Além das combinações de teor de água e temperatura outros fatores influenciam a qualidade fisiológica das sementes durante o armazenamento tais como: qualidade inicial, condições climáticas durante a maturação, fase de maturação no momento da colheita, ataque de pragas, doenças, tipo de embalagem e características do ambiente, especialmente temperatura e umidade relativa do ar (Carvalho e Nakagawa, 2000).

No sentido de preservar o potencial fisiológico das sementes, várias pesquisas vêm sendo desenvolvidas atualmente. Por exemplo, as sementes de cedro rosa (Cedrela angustifolia) armazenadas em câmara fria e seca $\left(10{ }^{\circ} \mathrm{C}\right.$ e $65 \%$ UR) permaneceram viáveis por até três anos independente da embalagem utilizada (saco de pano, saco plástico, saco de papel Kraft e caixas de madeira), embora apresentassem porcentagem de germinação inferior aos $23 \%$, enquanto que, em ambiente de laboratório sem controle das condições ambientais, a viabilidade das sementes foi conservada por apenas 75 dias em embalagem permeável (Piña-Rodrigues e Jesus, 1992).

Por outro lado, as sementes de branquilho (Sebastiania commersoniana) tiveram sua qualidade fisiológica preservada quando armazenadas em condições de 
laboratório por até cinco anos e meio em embalagens de pano, plástico ou vidro, mas, nas condições de câmara-fria tornaram-se viáveis por apenas 18 meses, nas embalagens plásticas ou de vidro (Santos e Paula, 2007).

Ao estudar o comportamento das sementes de ipêbranco (Tabebuia roseo-alba) e ipê-roxo (Tabebuia impetiginosa) durante o armazenamento, Borba Filho e Perez (2009) constataram que o ambiente natural de laboratório não se mostrou eficiente para a preservação da qualidade fisiológica das mesmas visto que permaneceram viáveis por apenas 60 dias. Porém, quando estocadas em câmara refrigeradora ( 14 a $20{ }^{\circ} \mathrm{C}$ e 74 a $82 \%$ UR) ou geladeira $\left(5 \pm 1{ }^{\circ} \mathrm{C}\right.$ e 38 a $\left.43 \%\right)$ mantiveram a qualidade fisiológica por até 300 dias nas diferentes embalagens (saco de papel, saco de polietileno e lata).

Dessa forma, o presente trabalho objetivou estudar o comportamento das sementes de Caesalpinia pyramidalis, acondicionadas em diferentes embalagens e ambientes de armazenamento.

\section{MATERIAL E MÉTODOS}

Os frutos de Caesalpinia pyramidalis foram coletados na Estação Experimental de São João do Cariri- PB em outubro de 2008 e conduzidos ao Laboratório de Análise de Sementes (LAS) do Centro de Ciências Agrárias (CCA) da Universidade Federal da Paraíba (UFPB) Campus II (Areia, PB).

Após beneficiadas, as sementes foram acondicionadas em dois tipos de embalagem: semi-permeável (constituída por recipiente plástico branco de polietileno com espessura de $0,5 \mathrm{~mm}$, que oferece certa resistência mas não impede a troca de vapor de água) e impermeável (vidro transparente com espessura de $3 \mathrm{~mm}$ ) hermeticamente fechadas e mantidas nos seguintes ambientes: em condições natural de laboratório, sem controle de temperatura e umidade relativa do ar $\left(27 \pm 3{ }^{\circ} \mathrm{C}\right.$ e $\left.64 \pm 20 \% \mathrm{UR}\right)$; freezer $\left(-18^{\circ} \mathrm{C}\right)$ e câmara seca $\left(19 \pm 5^{\circ} \mathrm{C}\right.$ e $74 \pm 20 \%$ UR) durante 225 dias. Inicialmente e a cada 45 dias as sementes foram avaliadas quanto a sua qualidade fisiológica por meio das seguintes determinações e testes:

Teor de água - determinado pelo método de estufa a $105{ }^{\circ} \mathrm{C}$ por 24 horas, (Brasil, 2009), utilizando-se quatro repetições de 25 sementes;

Primeira contagem de germinação - foi realizado juntamente com o teste de germinação onde foi calculada a porcentagem de plântulas normais no oitavo dia após a semeadura.
Teste de germinação - inicialmente as sementes foram escarificadas (lixa $\mathrm{n}^{\circ}$ 80) manualmente na região oposta ao hilo e, em seguida distribuídas em papel toalha previamente umedecido com volume de água equivalente a 2,5 vezes a massa do substrato seco sem adição posterior de água. Os rolos foram acondicionados em sacos plásticos transparente, de 0,04 mm de espessura, com a finalidade de evitar a perda de água por evaporação; em seguida foram mantidos em germinador tipo BOD regulado a $25{ }^{\circ} \mathrm{C}$ durante o período de 14 dias. As contagens foram realizadas diariamente, considerando como sementes germinadas aquelas que emitiram a raiz primária e a parte aérea e se encontravam aparentemente sadias (Brasil, 2009), com os resultados expressos em porcentagem.

Índice de velocidade de germinação (IVG) - foi realizado mediante contagem diária das plântulas, adotando como critério de avaliação contendo raíz 2 cm de comprimento e, calculado através da fórmula proposta por Maguire (1962);

Comprimento das plântulas - ao final do teste de germinação, as plântulas normais de cada repetição foram medidas com uma régua graduada em centímetros desde a extremidade da raiz até o meristema apical, sendo os resultados expressos em centímetros por plântula (Alves et al., 2006);

Massa seca das plântulas - os cotilédones das plântulas normais anteriormente medidas foram descartados, sendo as demais partes submetidas à secagem em estufa regulada em $65{ }^{\circ} \mathrm{C}$, até atingirem o peso constante, com os resultados expressos em gramas por plântula (Alves et al., 2006).

O delineamento utilizado foi inteiramente ao acaso, com os tratamentos distribuídos em esquema fatorial $(6 \times 3 \times 2)$, representados por seis períodos de armazenamento $(0,45,90,135,180$ e 225 dias $)$, três ambientes (laboratório, freezer e câmara seca), duas embalagens (vidro e plástico) e uma testemunha (avaliação no tempo zero). Os dados coletados foram submetidos à análise de variância. Para o fator período de armazenamento foi realizada a análise de regressão polinomial, utilizando-se o programa WINSTAT. Para escolha do modelo de regressão que melhor se ajustasse aos dados observados levou-se em consideração o fato de o desvio da regressão ser não significativo e, o modelo de maior ordem ser de grau significativo e, por último, o valor do coeficiente de determinação $\left(\mathrm{R}^{2}\right)$; do contrário, optou-se por apresentar os resultados da 
tendência seguida pelos pontos observados.

\section{RESULTADOS E DISCUSSÃO}

Inicialmente o teor de água das sementes (Figura 1) era de $8,9 \%$ e, ao longo do período de estocagem houve pequenas variações, ocorrendo um leve acréscimo ao final dos 225 dias de armazenamento em todos os ambientes e embalagens estudadas, registrando-se o teor de água das sementes acondicionadas no vidro na ordem de 9,8; 9,3 e 9,5\% e, na embalagem plástica de 9,5; 9,0 e 9,4\% nos ambientes de laboratório, câmara seca e freezer, respectivamente. Dessa forma, considerando-se o período inicial e final, independente das embalagens e ambientes, observa-se que o incremento do teor de água das sementes armazenadas foi inferior a $1 \%$.
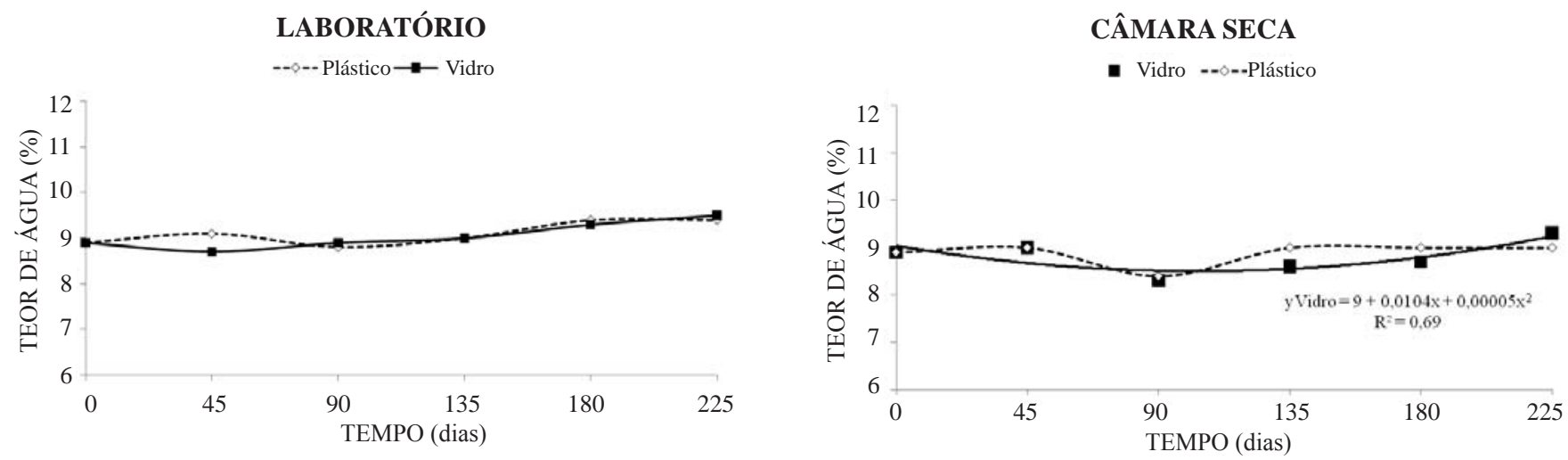

FREEZER

$\diamond$ Plástico $\mathbf{\square}$ Vidro

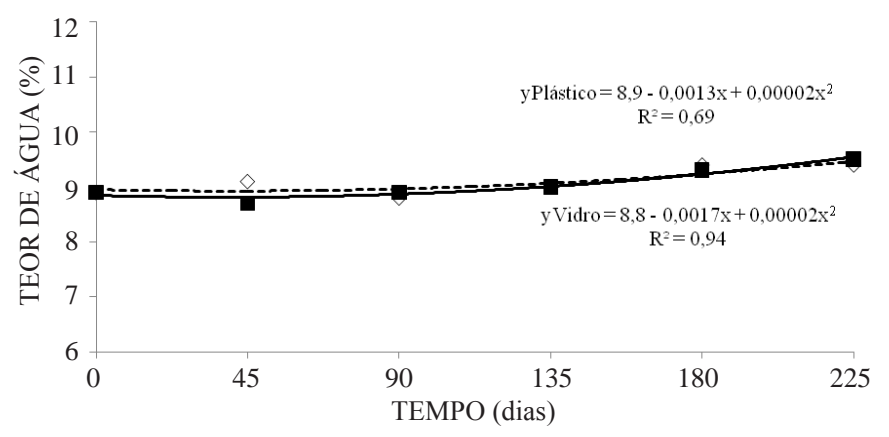

FIGURA 1. Teor de água das sementes de Caesalpinia pyramidalis acondicionadas em embalagem plástica e de vidro e, armazenadas em diferentes ambientes por 225 dias. Linha contínua = vidro, linha pontilhada $=$ plástico.

Todavia, vale ressaltar que, o pequeno aumento no teor de água das sementes embaladas em vidro ao final do armazenamento se deve a maior taxa respiratória das sementes mantidas nessa embalagem, proporcionando maior liberação de água e aumentando a umidade relativa do ar no interior do recipiente, uma vez que no momento da colheita pode haver desuniformidade de maturação dos frutos e, até mesmo das sementes contidas no interior de uma mesma vagem, fato característico de espécies pouco estudadas, possuindo dessa forma mecanismos naturais de sobrevivência (Carvalho e Nakagawa, 2000).

Com relação à porcentagem de germinação (Figura 2) constata-se um decréscimo nesta variável, para as sementes de catingueira armazenadas nos ambientes de laboratório e câmara seca e embaladas em plástico durante todo o período de estocagem, sendo esta 
diminuição mais expressiva no ambiente câmara seca. Quando as sementes foram acondicionadas no vidro e conservadas no ambiente de laboratório ocorreu uma redução na germinação dos 45 aos 135 dias de armazenamento, retomando a germinação inicial a partir dos 180 dias. Dessa forma, mesmo com as oscilações verificadas observa-se que as sementes permaneceram com alta viabilidade, quando acondicionadas em ambas embalagens e nos três ambientes estudados, em especial no ambiente freezer.
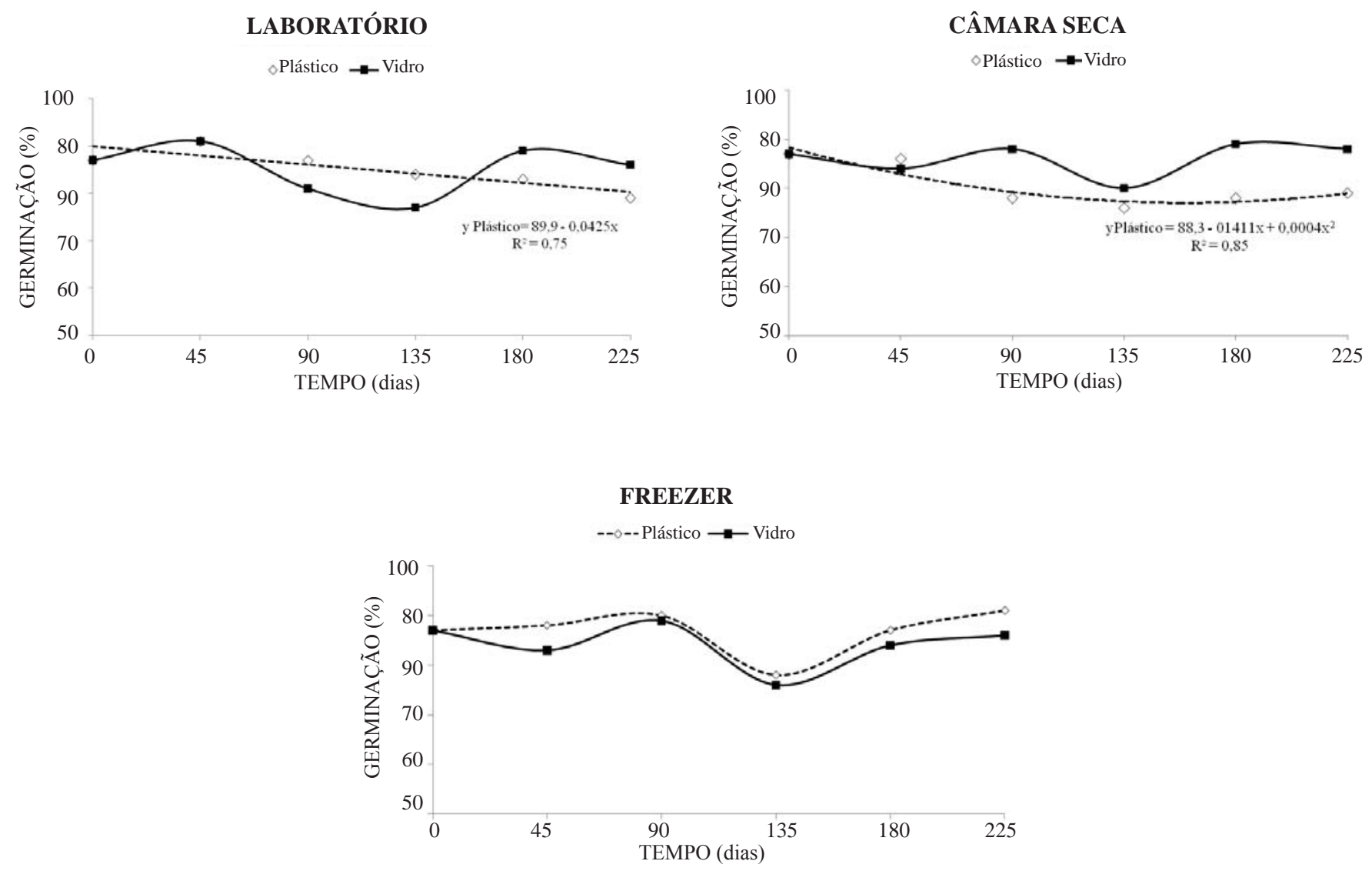

FIGURA 2. Germinação das sementes de Caesalpinia pyramidalis acondicionadas em embalagem plástica e de vidro e, armazenadas em diferentes ambientes por 225 dias. Linha contínua = vidro, linha pontilhada $=$ plástico.

Analisando-se o potencial fisiológico das sementes de catingueira armazenadas nos diferentes ambientes e embalagens (Figura 3 ) verifica-se, pelos dados da primeira contagem de germinação, realizada no oitavo dia após a semeadura, um acréscimo na germinação aos 45 dias, seguida de redução ao término do período de estocagem em ambas as embalagens empregadas. Numa análise geral verifica-se que houve redução na germinação por ocasião da primeira contagem, em todos ambientes e embalagens, nos dois últimos períodos de armazenamento, sendo esta redução mais drástica quando o armazenamento ocorreu no ambiente de laboratório. A causa provável de a embalagem vidro ter ocasionado maiores oscilações no teste de primeira contagem pode ser explicado pelo fato das sementes possuírem diferentes estádios de maturação por ocasião da colheita. De acordo com Piña-Rodriguez 
(1992) em muitas espécies florestais observa-se uma maturação diferenciada dentro do próprio fruto com a mesma coloração, assim, durante o armazenamento as sementes poderiam continuar seu ciclo de maturação e os picos observados seriam de sementes com maturação mais tardia.

\section{LABORATÓRIO}

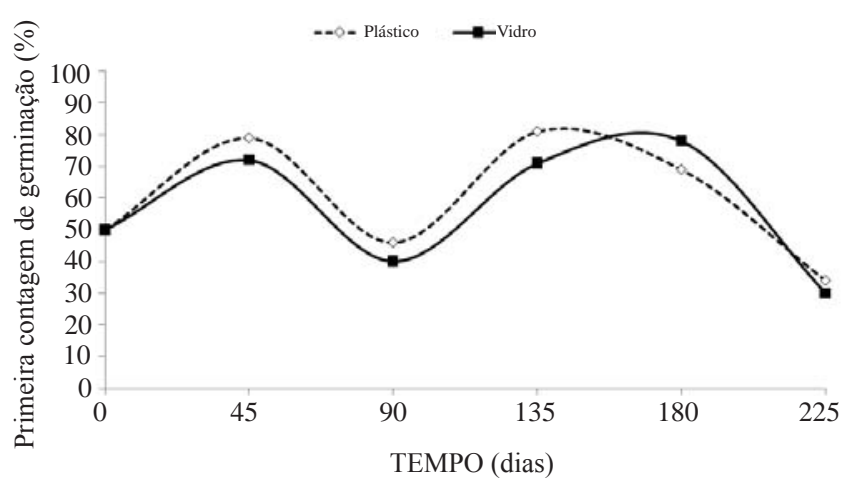

CÂMARA SECA

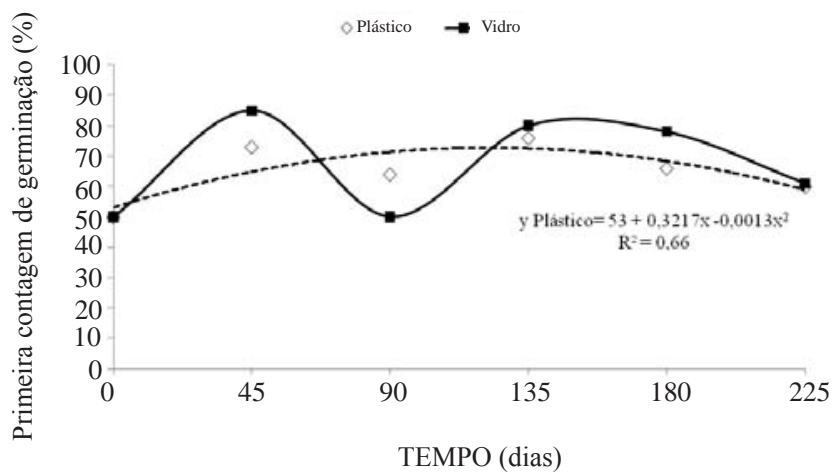

FREEZER

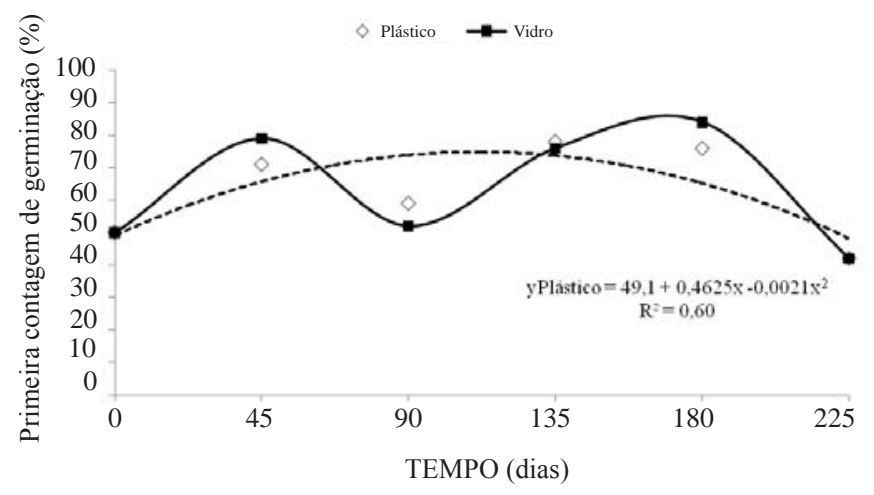

FIGURA 3. Primeira contagem de germinação das sementes de Caesalpinia pyramidalis acondicionadas em embalagem plástica e de vidro e, armazenadas em diferentes ambientes por 225 dias. Linha contínua = vidro, linha pontilhada $=$ plástico.

Para o índice de velocidade de germinação (Figura 4) foi constatado, de um modo geral, que as sementes acondicionadas nas embalagens de plástico e vidro, nos ambientes laboratório e freezer tiveram um pequeno acréscimo no vigor ao longo do armazenamento, ocorrendo um leve decréscimo ao final, contudo mantiveram o vigor inicial. Quanto ao acondicionamento das sementes em câmara seca, em ambas embalagens utilizadas, ocorreram maiores oscilações na velocidade de germinação comparativamente aos outros ambientes; no entanto, essas flutuações não foram expressivas e, novamente, o vigor inicial foi mantido nessas sementes, em quase todo o período de armazenamento. Vale destacar que o tipo de embalagem e ambientes empregados não interferiram significativamente na obtenção de valores mais altos, pois em todos os tratamentos obtiveramse valores semelhantes; todavia, a embalagem vidro proporcionou às sementes, a condição de se manterem mais vigorosas. A utilização de embalagens impermeáveis assegura a manutenção do teor de água, sendo adequada para uma conservação mais prolongada, com menor risco de perda da qualidade fisiológica das sementes por deterioração (CORLETT et al., 2007). 

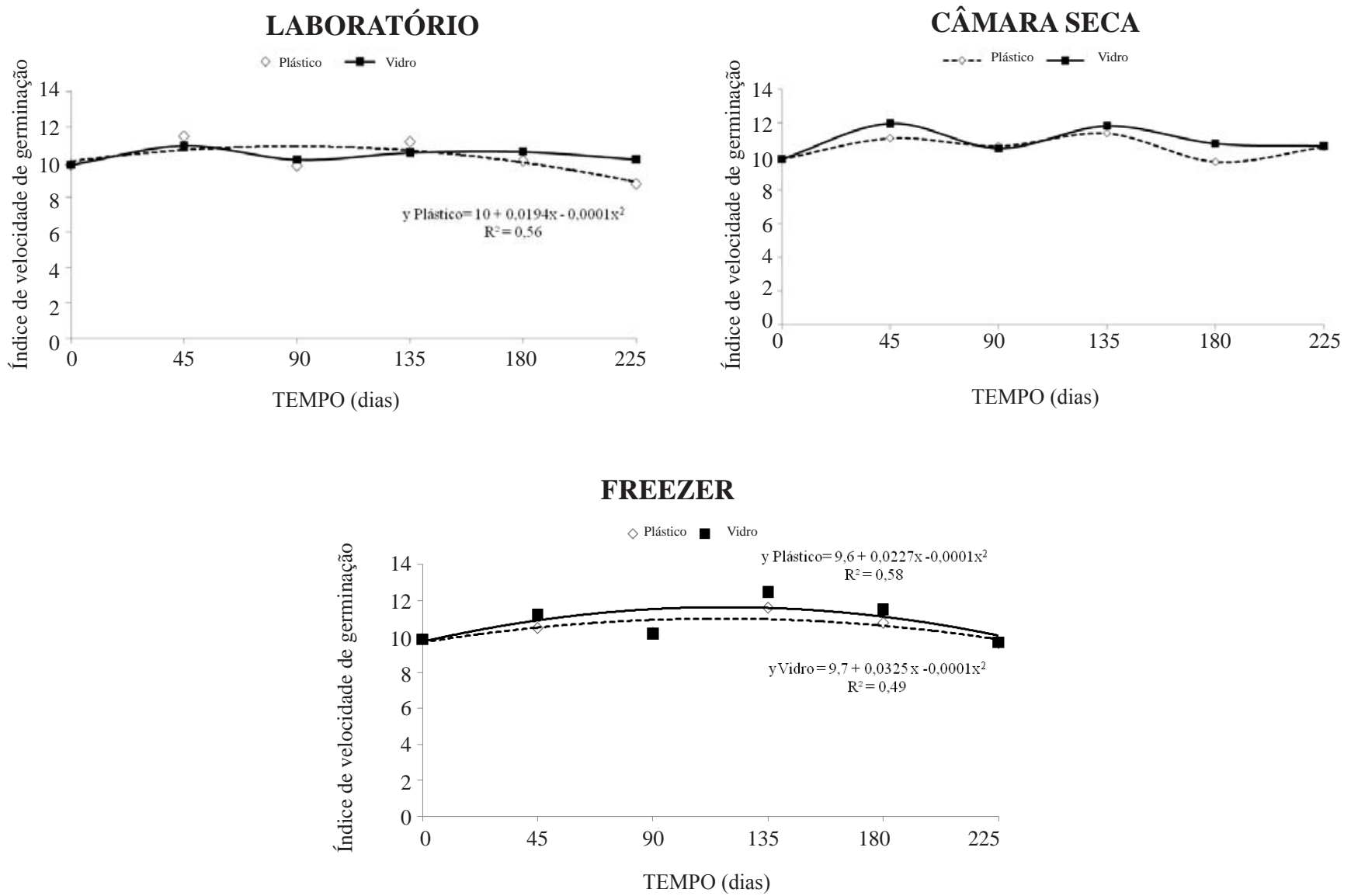

FIGURA 4. Índice de velocidade de germinação das sementes de Caesalpinia pyramidalis acondicionadas em embalagem plástica e de vidro e, armazenadas em diferentes ambientes por 225 dias. Linha contínua $=$ vidro, linha pontilhada $=$ plástico .

Em relação ao comprimento de plântulas de catingueira (Figura 5), as sementes acondicionadas, nas embalagens de plástico e vidro tiveram de um modo geral comportamento similar dentro de cada ambiente analisado. Observa-se que no período de 45 dias, em todos os ambientes e embalagens estudados, houve aumento no comprimento das plântulas quando comparado com o inicial. Este comportamento está de acordo com o observado nos outros testes de vigor (Figuras 3 e 4) evidenciando, dessa forma que, as sementes, em especial, às florestais após algum tempo conseguem uma maior uniformização no processo de maturação melhorando, assim, seu desempenho. Resultados similares também foram observados por Nunes et al. (2008) em sementes de sempre-viva (Syngonanthus elegans), pois a desuniformidade de maturação na mesma planta e entre elas dificultou a uniformidade do lote de sementes e, consequentemente, a necessidade da utilização de um período de pós-maturação.

Novamente as sementes de catingueira acondicionadas nos ambientes de laboratório e freezer atingiram a mesma tendência de comportamento e valores semelhantes quando analisadas por meio do teste de massa seca de plântulas (Figura 6). Dessa forma, observa-se uma diminuição gradativa do vigor dessas sementes ao longo da estocagem e um leve acréscimo ao final do período. Este fato, provavelmente, esteja relacionado com os diferentes estádios de maturação das sementes, tendo em vista que estas, ao atingirem a maturidade em tempos diferenciados, poderão paulatinamente germinar e desenvolverem as plântulas ao longo do tempo, nos diferentes períodos do armazenamento. Também, cabe destacar que, no ambiente de câmara seca, as sementes embaladas em plástico tiveram comportamento semelhante ao dos demais ambientes, 
com maiores oscilações quando acondicionadas em vidro, principalmente, no período de 90 a 180 dias. Possivelmente, diferenças de maturação das sementes acondicionadas nesta embalagem impermeável, ao longo do armazenamento poderão induzi-las a expressarem a germinação e por conseguinte o vigor das plântulas de forma diferenciada, ao longo do tempo. Segundo Aroucha et al. (2007) algumas espécies como soja adquirem a maturidade fisiológica (máximo vigor) no final do período de enchimento das sementes, enquanto outras espécies atingem a máxima qualidade durante um período de repouso, após máximo acúmulo de matéria seca, a exemplo do arroz e feijão.

\section{LABORATÓRIO}

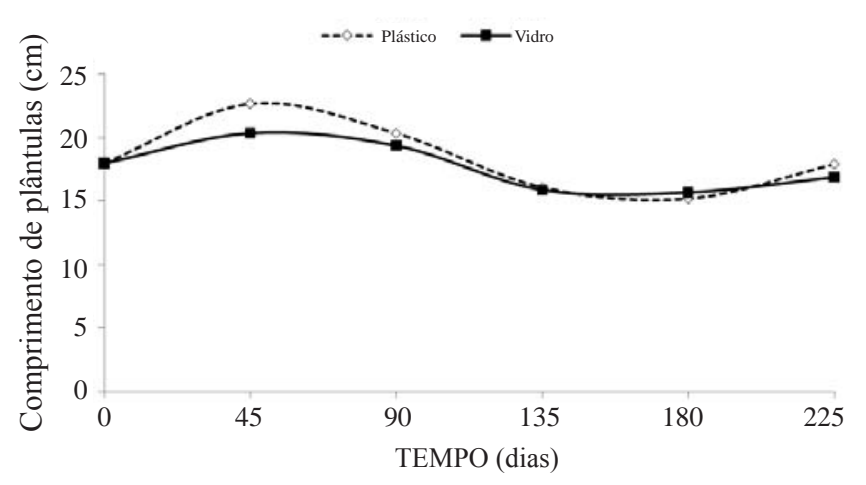

CÂMARA SECA

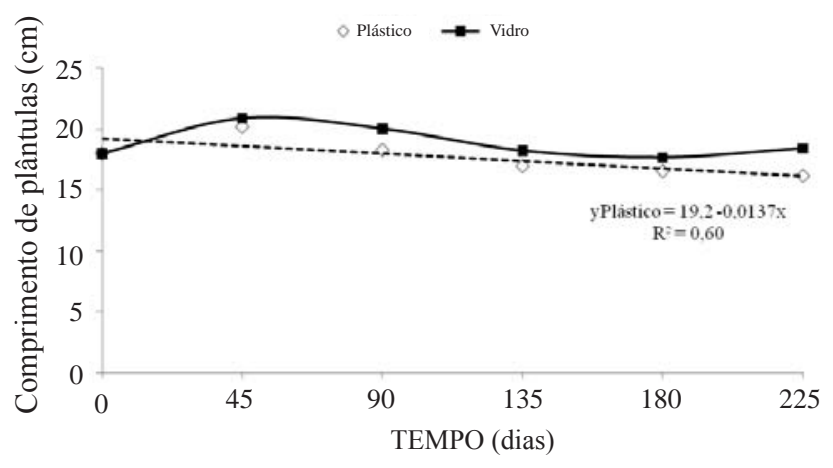

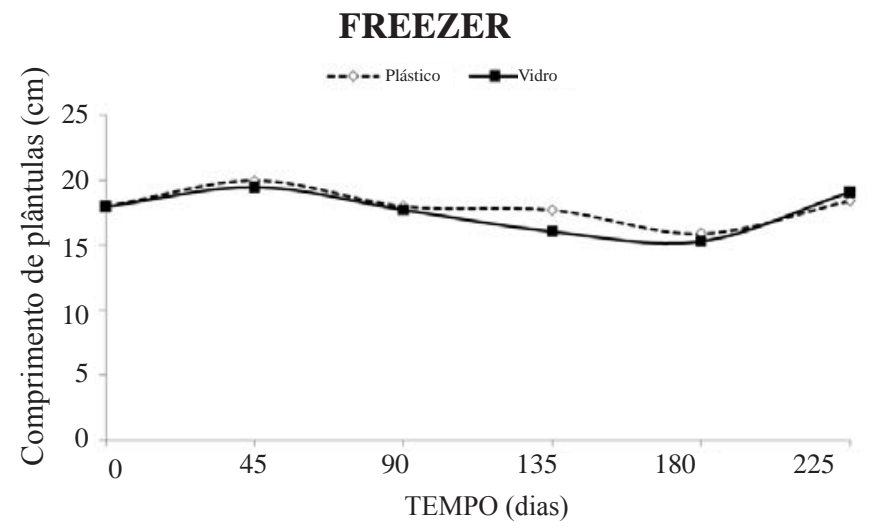

FIGURA 5. Comprimento de plântulas de Caesalpinia pyramidalis oriundas de sementes acondicionadas em embalagem plástica e de vidro e, armazenadas em diferentes ambientes por 225 dias. Areia-PB, 2009. Linha contínua $=$ vidro, linha pontilhada $=$ plástico. 
LABORATÓRIO

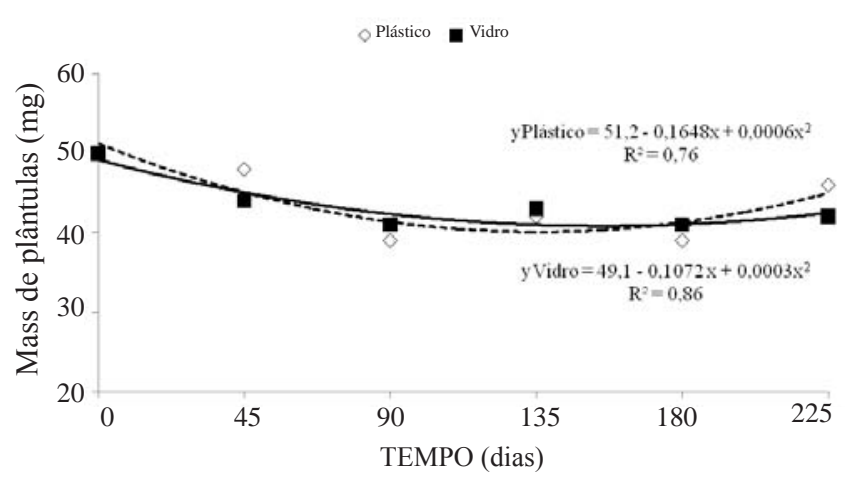

CÂMARA SECA

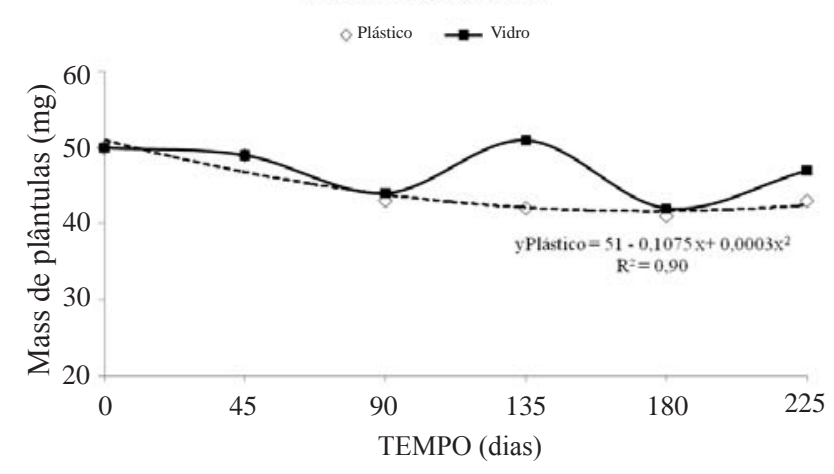

FREEZER

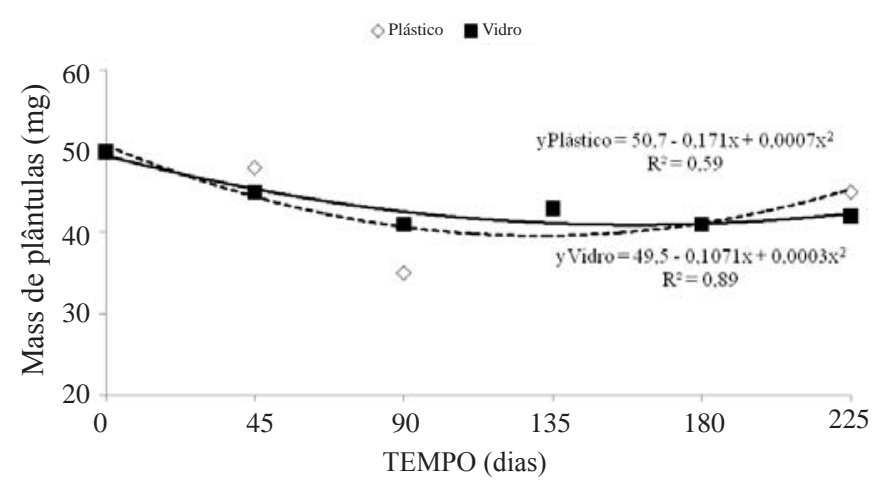

FIGURA 6. Massa seca de plântulas de Caesalpinia pyramidalis oriundas de sementes acondicionadas em embalagem plástica e de vidro e, armazenadas em diferentes ambientes por 225 dias. Linha contínua = vidro, linha pontilhada $=$ plástico.

\section{CONCLUSÕES}

A viabilidade e o teor de água das sementes de Caesalpinia pyramidalis são mantidos em todos os ambientes e embalagens estudadas neste trabalho.

O vigor das sementes, quando analisado pela primeira contagem de germinação, é melhor conservado quando as mesmas são acondicionadas em plástico nos ambientes de câmara seca e freezer até o período de 135 dias.

As oscilações, constatadas no processo germinativo, ocorridas nas sementes acondicionadas nas diferentes embalagens são ocasionadas pelos diferentes graus de uniformidade de maturação das sementes no momento de sua colheita.

\section{REFERÊNCIAS}

ALVES, E.U.; BRUNO, R.L.A.; OLIVEIRA, A.P.; ALVES, A.U.; ALVES, A.U. Ácido sulfúrico na superação da dormência de unidades de dispersão de juazeiro (Zizyphus joazeiro Mart.). Revista Árvore, v.30, n.2, p.187-195, 2006.

AROUCHA, E.M.M.; SILVA, R.F.; BALBINOT, E.; NUNES, G.H.S. Qualidade fisiológica de sementes de mamão após o armazenamento dos frutos e de sementes. Revista Caatinga, v.20, n.3, p.136-143, 2007.

AZEVEDO, M.R.Q.A.; GOUVEIA, J.P.G.; TROVÃO, D.M.M.; QUEIROGA, V.P. Influência das embalagens e condições de armazenamento no vigor de sementes de 
gergelim. Revista Brasileira de Engenharia Agrícola e Ambiental, v.7, n.3, p.519-524, 2003.

BORBAFILHO, A.B.; PEREZ, S.C.J.G.A. Armazenamento de sementes de ipê-branco e ipê-roxo em diferentes embalagens e ambientes. Revista Brasileira de Sementes, v.31, n.1, p.259-269, 2009.

BRASIL. Ministério da Agricultura, Pecuária e Abastecimento. Regras para análise de sementes. Ministério da Agricultura, Pecuária e Abastecimento. Secretaria de Defesa Agropecuária. Brasília, DF: MAPA/ ACS, 2009. 395p.

CARVALHO, N.M.; NAKAGAWA, J. Sementes: ciência, tecnologia e produção. 4.ed. Jaboticabal, SP: FUNEP, 2000. 588p.

CORLETT, F.M.F.; BARROS, A.C.S.A.; VILLELA, F.A. Qualidade fisiológica de sementes de urucum armazenadas em diferentes ambientes e embalagens. Revista Brasileira de Sementes, v.29, n.2, p.148-158, 2007.

FIGLIOLIA, M.B.; PIÑA-RODRIGUES, F.C.M. Manejo de sementes de espécies arbóreas. São Paulo: Instituto Florestal, 1995. 59p. (Série Registros, n. 15).

KRZYZANOWSKI, F.C.; VIEIRA, R.D.; FRANÇA NETO, J.B. (Ed.). Vigor de sementes: conceitos e testes. cap. 2. Londrina: ABRATES, 1999. p.1-21.

MAGUIRE, L.D. Speed of germination - aid in selection and evolution for seedling emergence and vigor. Crop Science, v.2, n.2, p.176-177, 1962.

MAIA, G.N. Catingueira. In: MAIA, G.N. Caatinga: árvores e arbustos e suas utilidades. São Paulo: Leitura e Arte, 2004. p.159-165.
MATALLO JÚNIOR, H.A desertificação no Brasil. In: OLIVEIRA, T.S. etal.(Ed.). Agricultura, sustentabilidade e o semi-árido. Fortaleza: UFC, 2000. p.89-113.

MEDEIROS, A.C.S.; EIRA, M.T.S. Comportamento fisiológico, secagem e armazenamento de sementes florestais nativas. Colombo: Embrapa Floresta, 2006. 13p. (Embrapa Floresta. Circular técnica,127).

NUNES, S.C.P.; NUNES, U.R.; FONSECA, P.G.; GRAZZIOTTI, P.H.; PEGO, R.G.; MARRA, L.M. Época, local de colheita e armazenamento na qualidade fisiológica da semente de sempre-viva (Syngonanthus elegans (Bong.) Ruhland - Eriocaulaceae). Revista Brasileira de Sementes, v.30, n.1, p.32-39, 2008.

PIÑA-RODRIGUES,F.C.M.;JESUS,R.M.Comportamento das sementes de cedro-rosa (Cedrela angustifolia S. et. Moc) durante o armazenamento. Revista Brasileira de Sementes, v.14, n.1, p.31-36, 1992.

PONTES, C.A.; CORTE, V.B.; BORGES, E.E.L.; SILVA, A.G.; BORGES, R.C.G. Influência da temperatura de armazenamento na qualidade das sementes de Caesalpinia peltophoroides Benth. (sibipiruna). Revista Árvore, v.30, n.1, p.43-48, 2006.

SANTOS, S.R.G.; PAULA, R.C. Qualidade fisiológica de sementes de Sesbatinia commersoniana (Baill.) Smith \& Downs (branquilho - Euphorbiaceae) durante o armazenamento. Scientia Forestalis, n.74, p.87-94, 2007.

SCHORN, L.A. Aspectos gerais da produção de sementes. Disponível em: <htt://home.ufrb.br/Ischorn/ silviculturaI.html>. Acesso em: 12 de maio 2009. 